\title{
CORRESPONDENCE
}

\section{PARADOXICAL LID RETRACTION IN UNILATERAL CONGENITAL PTOSIS}

\section{To the Editorial Committee of the British Journal of Ophthalmology}

SIRS-The interesting case described and illustrated by Jain, Sethi, and Parkash (British Journal of Ophthalmology, 1956, 40, 558), shows several points characteristic of a congenital superior rectus palsy, where the resulting vertical deviation has in the course of time become largely concomitant. The ptosis on the affected side is a pseudo-ptosis, disappearing when the affected eye looks straight ahead instead of downwards. The "paradoxical" lid retraction on the unaffected side is the normal elevation of the upper lid accompanying the normal elevation of a healthy eye.

It is not uncommon for the affected eye in a case of congenital superior rectus palsy to be habitually used for fixation when the patient is looking downwards, and this explains why the visual acuity has been retained. The unaffected eye is normally responsible for fixation in all other directions, hence the reappearance of the ptosis when the unaffected eye is uncovered.

6 Devonshire Place, Yours faithfully, G. J .O. BRIDGEMAN T. KeITH LYLE LONDON, W.1.

21 December, 1956.

\section{BOOK REVIEWS}

An Atlas of Diseases of the Eye. By E. S. Perkins and P. Hansell, 1957. Pp. 91, figs. Churchill, London. (42s.)

As stressed by Sir Stewart Duke-Elder in the foreword, the only satisfactory way to study medicine is by the constant observation of patients.

However, when time is limited, as in teaching undergraduates, it is often difficult to present to a class a comprehensive cross-section of common disorders. The problems in finding an intricate case of iritis, let alone one of Coats's disease, are well known to all teachers.

This new atlas of eye diseases will greatly help in filling up these gaps. It consists of about two hundred beautiful illustrations, the great majority in colour, with a brief but adequate description of the condition on the adjacent page. The external conditions of the eye are illustrated by colour photography, with certain features accentuated by the artist, and the internal conditions by fundus photography or painting; the standard is such that it is sometimes quite difficult at first glance to distinguish the two.

Reproduction is by eight-colour photo-lithography on fine quality cartridge paper, and the result must be one of the finest productions in medical literature. The process is costly and it is no surprise to learn that the sale price represents only one-tenth of cost, the remainder being generously subsidized by Roche Products Limited.

With this Atlas, the undergraduate and medical practitioner can quickly become acquainted with the eye. The student of ophthalmology can quickly revise his knowledge of the clinical appearance of eye diseases, and the ophthalmologist will find the book of great assistance in his teaching.

Because of the costly process, the atlas is not fully comprehensive, and this is the only criticism. Squints, for instance, are not fully appreciated by many practitioners, but this subject is not included. 